\title{
Anterior Cervical Arachnoid Cyst with Rapid Progressive Quadriparesis in a Pregnant Woman: A Case Report
}

\author{
Reza Bahrami ${ }^{1}$ Hossein Safari ${ }^{1}$ \\ ${ }^{1}$ Department of Neurosurgery, Ahvaz Jundishapur University of \\ Medical Sciences, Ahvaz, Iran \\ Indian J Neurosurg 2015;4:52-54.
}

\begin{abstract}
Address for correspondence Dr. Hossein Safari, MD, Department of Neurosurgery, Ahvaz Jundishapur University of Medical Sciences, Ahvaz, P.O. Box 61357-33118, Iran (e-mail: Safary64@yahoo.com).
\end{abstract}

\begin{abstract}
Arachnoid cyst in the spine frequently arises from posterior to the spinal cord in the

Keywords

- arachnoid cyst

- cervical

- pregnant

- quadriparesis thoracic region. Anterior cervical arachnoid cyst is a rare entity of which only a few cases have been reported in the literature. Herein, we present a 26-year-old pregnant woman at 22 weeks of gestation with a history of rapid progressive quadriparesis that harbors a large ventral located cervical arachnoid cyst. She emergently underwent posterior laminectomy and cyst wall fenestration. Postoperatively, her muscles strength was fully recovered without any neurologic deficit.
\end{abstract}

\section{Introduction}

Anterior cervical location of arachnoid cyst is rare, and only few cases have been reported in the literature. ${ }^{1-14}$ It commonly arises from posterior to the spinal cord in the thoracic spinal region, ${ }^{2}$ and those arising at the anterior cervical location are distinctly rare. ${ }^{1-3,15,16}$ Intradural spinal arachnoid cysts appear to result from an alteration of the arachnoid trabeculae. The majorities of them are idiopathic, whereas previous trauma or arachnoiditis have been anecdotally described. ${ }^{17,18}$ Treatment of dorsally located arachnoid cyst is laminectomy or laminotomy through a posterior cervical approach. ${ }^{19}$ According to the case reports and other literature, treatment of ventrally located cervical arachnoid cysts is both posterior laminectomy and ventral corpectomy. ${ }^{1-12}$

In this case report, we present an anteriorly located cervical arachnoid cyst in a pregnant woman with acute quadriparesis who was operated via posterior laminectomy and fully recovered her muscular strength without neurologic deficit or surgical complication.

\section{Case Presentation}

A 26-year-old pregnant woman at 22 weeks of gestation was admitted in our clinic with a history of weakness in upper and lower extremities that progressed from 2 weeks ago. At the time of hospital admission, her examination revealed quadriparesis with $4 / 5$ motor power in proximal and distal muscles of upper and lower extremities. Cervical magnetic resonance imaging (MRI) showed a ventrally located lesion behind $\mathrm{C} 4$ and $\mathrm{C} 5$ vertebral body with signal intensity similar to cerebrospinal fluid (CSF) with no enhancement in contrast administration (-Fig. 1). She was taken up for an emergency surgery because she developed rapid deterioration of power from $4 / 5$ to $2 / 5$ during the day of admission.

She underwent a standard laminotomy of C4 and C5 and a partial facetectomy of $\mathrm{C} 5$. While positioning the patient in prone position, precautions were taken to avoid any pressure on abdomen. After laminotomy, dura matter was opened from midline with minimal manipulation of cervical cord from lateral aspect, subsequently dentate ligament was cut and arachnoid cyst wall was exposed from space between the $\mathrm{C} 4$ and $\mathrm{C} 5$ rootlets. After resection of lateral wall of cyst, it was drained and cord decompression was achieved.

Within a few days of surgery, power in her limbs improved to $5 / 5$. The patient became symptom free on long-term follow-up. Pathologic report from the cyst wall confirmed the diagnosis of arachnoid cyst. published online March 20, 2015
DOI http://dx.doi.org/ $10.1055 / \mathrm{s}-0035-1549060$. ISSN 2277-954X.
(C) 2015 Neurological Surgeons' Society of India
License terms

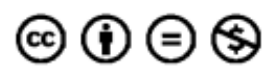




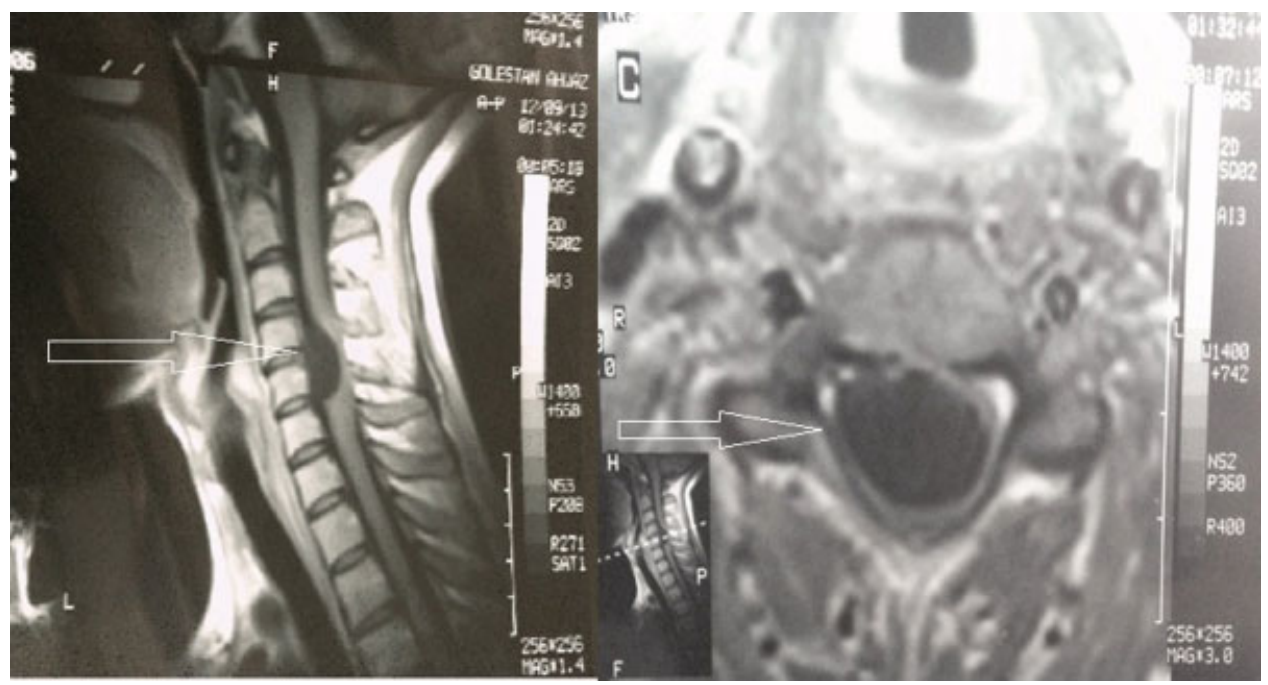

Fig. 1 T1 with contrast administration (axial and sagittal view).

\section{Discussion}

Anterior cervical spinal arachnoid cysts are relatively uncommon lesions that may be intradural or extradural. It is well known that the majority of the arachnoid cysts are located in the dorsal thoracic spine. Only a few cases of anteriorly located arachnoid cyst have been reported. $^{1-14,20,21}$

Three cases reported with the arachnoid cyst located at the anterior cervical have been treated with anterior corpectomy and reconstruction. ${ }^{13,14,22}$ One case was operated through the partial median corpectomy for C2-C3 intradural arachnoid cyst. ${ }^{14}$

We reported a rare case of anteriorly located arachnoid cyst in a pregnant woman, who developed acute-onset quadriparesis. Similar case has never been reported in the literature. We postulate that pregnancy might have been a factor in causing increment in cyst size.

\section{Acknowledgments}

Our special thanks go to members of Golestan Hospital Clinical Development Research Unit and Molook Salemzadeh for helping us in submission.

\section{References}

1 Palmer JJ. Cervical intradural arachnoid cyst in a 3-year-old child. Report of a case. Arch Neurol 1974;31(3):214-215

2 Kazan S, Ozdemir O, Akyüz M, Tuncer R. Spinal intradural arachnoid cysts located anterior to the cervical spinal cord. Report of two cases and review of the literature. J Neurosurg 1999;91(2, Suppl):211-215

3 Safriel YI, Sanchez G, Jhaveri HS. Giant anterior cervicothoracic arachnoid cyst. Spine 2002;27(15):E366-E368

4 Takahashi S, Morikawa S, Egawa M, Saruhashi Y, Matsusue Y. Magnetic resonance imaging-guided percutaneous fenestration of a cervical intradural cyst. Case report. J Neurosurg 2003;99(3, Suppl):313-315
5 Muthukumar N. Anterior cervical arachnoid cyst presenting with traumatic quadriplegia. Childs Nerv Syst 2004;20(10): 757-760

6 Hamamcioglu MK, Kilincer C, Hicdonmez T, Simsek O, Birgili B, Cobanoglu S. Giant cervicothoracic extradural arachnoid cyst: case report. Eur Spine J 2006;15(Suppl 5):595-598

7 Maiuri F, laconetta G, Esposito M. Neurological picture. Recurrent episodes of sudden tetraplegia caused by an anterior cervical arachnoid cyst. J Neurol Neurosurg Psychiatry 2006;77(10): $1185-1186$

8 Shehu BB, Hassan I. Cervicothoracic arachnoid cyst in a patient with neurofibromatosis: case report. East Afr Med J 2006;83(9): 515-517

9 Guzel A, Tatli M, Yilmaz F, Bavbek M. Unusual presentation of cervical spinal intramedullary arachnoid cyst in childhood: case report and review of the literature. Pediatr Neurosurg 2007; 43(1):50-53

10 Kutlay M, Qolak A, Demircan N, Akin O. Craniocervical junction arachnoid cyst causing hydrocephalus: case report and review of the literature. Mil Med 2007;172(6):669-672

11 Jain F, Chaichana KL, McGirt MJ, Jallo GI. Neonatal anterior cervical arachnoid cyst: case report and review of the literature. Childs Nerv Syst 2008;24(8):965-970

12 Gezici AR, Ergün R. Cervical anterior intradural arachnoid cyst in a child. Acta Neurochir (Wien) 2008;150(7):695-698, discussion 698

13 Banczerowski P, Lipóth L, Vajda J, Veres R. Surgery of ventral intradural midline cervical spinal pathologies via anterior cervical approach: our experience. Ideggyogy Sz 2003;56(3-4): $115-118$

14 Muhammedrezai S, Ulu MO, Tanriöver N, Moghaddam AM, Akar Z. Cervical intradural ventral arachnoid cyst resected via anterior corpectomy with reconstruction: a case report. Turk Neurosurg 2008;18(3):241-244

15 Chan RC, Thompson GB, Bratty PJ. Symptomatic anterior spinal arachnoid diverticulum. Neurosurgery 1985;16(5): 663-665

16 Chen HJ, Chen L. Traumatic interdural arachnoid cyst in the upper cervical spine. Case report. J Neurosurg 1996;85(2):351-353

17 Dyck P. Myelopathy due to spinal arachnoid cyst. A case report. Spine 1986;11(1):80-82

18 Gelabert-González M, Cutrín-Prieto JM, García-Allut A. Spinal arachnoid cyst without neural tube defect. Childs Nerv Syst 2001; 17(3):179-181 
19 Asazuma T, Sato M, Ichimura S, et al. Endodermal cyst of the cervical spine treated by an anterior approach for resection and shunting. J Spinal Disord Tech 2002;15(3):258-260

20 Kuroiwa T, Takeuchi E, Yamada K, Ohta T, Miyaji Y, Onomura T. An intradural arachnoid cyst of the craniovertebral junction; a case report [in Japanese]. No Shinkei Geka 1991;19(11):1097-1099
21 Takanashi Y, Mochimatsu Y, Shyudo T, Yamamoto I. A case report of an arachnoid cyst in the craniovertebral junction [in Japanese]. No To Shinkei 1995;47(1):68-70

22 Srinivasan US, Bangaari A, Senthilkumar G. Partial median corpectomy for C2-C3 intradural arachnoid cyst: case report and review of the literature. Neurol India 2009;57(6):803-805 